\title{
Design for poverty alleviation and craft revitalization in rural China from an actor-network perspective: the case of bamboo-weaving in Shengzhou
}

\author{
Wenjia $\mathrm{Li}^{1^{*}}$, Ziwei $\mathrm{Li}^{1}$ and Huaiyun $\mathrm{Kou}^{2 *}$
}

\begin{abstract}
Design for poverty alleviation (DPA) is becoming an active promoter and effective practice form of rural social innovation. This study aims to explore the sustainable, collaborative design path of rural poverty alleviation. Based on actor network theory, this study analyzes the poverty alleviation process of rural actor network construction and participatory translation through the perspective of design integration. The case study chooses the traditional Chinese handicraft, Shengzhou bamboo weaving, to discuss the key links and elements of sustainability such as the role, benefits, and interaction of multiple actors. The staged effectiveness and social impact of the design integration are evaluated by questionnaire surveys, in-depth interviews, qualitative and quantitative data collections, a logistic regression model was used to test for significant effects while adjusting for multiple factors simultaneously. The analysis shows that although DPA is difficult to realize the fundamental adjustment of the rights and interests of rural craftsmen, it plays a key role in guiding the development of industrial goals, expected economic and social benefits, brings huge driving force and implementation effect to rural social innovation. The actor network theory solves the problem of separation between the individual and network attributes of DPA among stakeholders, and provides an innovative basis for rural social innovation to choose effective design intervention and mechanisms to balance the rights and interests of various stakeholders.
\end{abstract}

Keywords: Design for poverty alleviation, Rural communities, Craft revitalization, Actor network, Bamboo-weaving, Regression analysis

\section{Introduction}

Social innovation is recognized to have huge social energy and it can solve wicked and complex integrated problems [1]. New governance methods and social innovation design methods assist society sustainable transformation [2]. Nowadays, the theory of social innovation has received increasing attention and emphasis from

\footnotetext{
*Correspondence: liwenjia@usst.edu.cn; khy@tongji.edu.cn

${ }^{1}$ College of Communication and Art Design, University of Shanghai for Science and Technology, No. 516, Jungong Road, Yangpu District, Shanghai 200093, China

${ }^{2}$ College of Architecture and Urban Planning, Tongji University, No. 1239, Siping Road, Yangpu District, Shanghai 200092, China
}

academic and practical circles worldwide [3]. Design for poverty alleviation (DPA) has become an important form and effective tool of rural social innovation and design. This intermediary is facing the problem of how to contribute to the sustainable development of rural areas [4]. The social innovation in rural areas needs to be able to meet social needs and create new social relationships or cooperation at the same time [5]. This is beneficial to society and can improve the innovation of social action capabilities [6], "No Poverty" is the global vision and priorities of the development framework of the United Nations Sustainable Development Goals (SDGs) [7]. From the perspective of social innovation, the entry point
Springer Open

(c) The Author(s) 2021. Open Access This article is licensed under a Creative Commons Attribution 4.0 International License, which permits use, sharing, adaptation, distribution and reproduction in any medium or format, as long as you give appropriate credit to the original author(s) and the source, provide a link to the Creative Commons licence, and indicate if changes were made. The images or other third party material in this article are included in the article's Creative Commons licence, unless indicated otherwise in a credit line to the material. If material is not included in the article's Creative Commons licence and your intended use is not permitted by statutory regulation or exceeds the permitted use, you will need to obtain permission directly from the copyright holder. To view a copy of this licence, visit http://creativecommons.org/licenses/by/4.0/. The Creative Commons Public Domain Dedication waiver (http://creativeco mmons.org/publicdomain/zero/1.0/) applies to the data made available in this article, unless otherwise stated in a credit line to the data. 
of DPA risen from human needs to social needs, paying more attention to social justice and emphasizing improving the basic survival needs of social groups and the overall sustainable development needs of human society, so as to realize the goal of socially innovative design intervention and targeted poverty alleviation [8].

The urban communities have always been the focus of community innovation due to their resource and location advantages. The urbanization has exacerbated the gap between urban and rural areas, resulting in unequal resources. The less employment in rural areas limits the increase of residents' wealth and numbers of rural craftsmen flock to cities to find new jobs. The protection and development of rural handicrafts has become an important anti-poverty strategy that the government and academia attach importance to. As an important part of cultural heritage [9-12], handicrafts can reflect the cultural traditions of a certain region or nation [13]. Governments around the world are exploring ways to preserve and inherit intangible cultural heritage so as to continue the cultural heritage of the endless creation of various ethnic groups [14]. With the accumulation of history, many villages in China have created intangible cultural heritage with their own characteristics. These traditional handicrafts are not only the treasures of folk culture, but also the epitome of national aesthetics, skills, life and history. However, due to the impact of industrialization, global integration and the change of lifestyle, Chinese traditional handicrafts are facing the dilemma of preservation and development. Under the circumstances, the study on the role of design in the process of rural handicraft revitalization and poverty alleviation has become an urgent and realistic need in the level of national governance and civil society consciousness.

However, in the current practice and research on DPA, the main problems are that complexity of interest structure within community and diversity of participating subjects in the DPA process, in which there is no final conclusion on the participation methods and effects for designers. Also, there are few studies on analyzing the complex process and exploring the key mechanisms how design getting involved from the perspective of actors. Under the circumstances, the study on the role of design in the process of rural handicraft revitalization and poverty alleviation has become an urgent and realistic need in the level of national governance and civil society consciousness. From the perspective of actors, this study was conducted to explore a sustainable operation model of DPA by analyzing the specific process of how design engaging in and the key elements and core values of actor participation in DPA. Our research will be presented in the following organization: In Literature review section, we will show the design for sustainable traditional craftsmanship and poverty alleviation, and theoretical framework of the Actor-Network Theory. In Methodology, the context of Shengzhou bamboo weaving, the case of this study is particular described. Then we introduce the actors network design for poverty alleviation, the construction of participatory translation in the actor network, the dissent and Resolution, and the social impact analysis of design for poverty alleviation. In Results and discussion section, the results obtained is presented and discussed and considering our research and previous literature. Based on the results and discussion, the conclusion is drawn, and the limitations and future research are addressed at the end of the paper.

\section{Literature review \\ Design for sustainable traditional craftsmanship and poverty alleviation}

From the design perspective, sustainability is a strategic activity to construct and develop solutions, and an important way to resolve the cultural identity crisis and revitalize the culture and economy of local communities. The government, designers, and local craftsmen jointly contribute to the revival and sustainable development of craftsmanship. Thai designer Korakot Aromdee emphasized the importance of dialogue between designers and space, inspired by hand-woven fishing nets and traditional techniques of making kites, promoted the industrialization process of bamboo weaving [15]. The Vietnamese government established a training base in the handicraft village, introduced an online teaching model, and stepped up the cultivation and learning process of handicrafts. At the same time, the government consciously introduced modern advanced technology and paid attention to the establishment of standard industry norms [16]. Japan used the "machining movement" as a social innovation to rejuvenate the countryside, which had positive impacts on the improvement of landscape and environmental quality, the preservation of cultural heritage, the promotion of health and welfare, and the ecological protection. In the process of design for poverty alleviation, emphasizing the concept of joint participation and sustainable operation can better promote the inheritance and development of handicrafts [17]. The collaborative work usually involves in contemporary craft practice. In Bangchaocha community in Thailand [18], designers integrate all stakeholders in the community to participate in learning, create an environment and stimulation for craftsmen, and help retrieve local cultural identities and cultural assets. In the Chinese countryside, the key issue in the contemporary inheritance of handicrafts lies in how traditional handicrafts from the past can be integrated into contemporary society. Song [19] proposed methods of protecting traditional handicrafts 
from the perspective of cultural production, emphasizing both inheritance and development; stressing both spirituality and practicality and economy. Liu [20] proposed to establish a monitoring and evaluation system for the protection of traditional handicrafts in the era of cultural and creative industries, and establish a "cultural early warning" mechanism. China is deepening and expanding the research and practice activities on the inheritance and development of traditional handicrafts nationwide, and it is fully suitable for the methods, approaches, technologies and models of the sustainable development of traditional handicrafts in order to resolve the survival crisis faced by handicrafts.

Poverty is a comprehensive result of economic, environmental, and social factors. The purpose of designing poverty alleviation is to serve people in poor areas to help them get rid of poverty, improve the quality of life within the ecosystem capacity. The research of DPA mainly focuses on the perspectives of ethics, service and operative system. In the process of DPA, design ethics is reflected in the balance of people, resources and the environment, which is related to 'technology, sustainability and responsibility" [21]. The purpose of design participation in poverty alleviation is not only the design of things that meet the needs of poor areas and groups, more importantly, it is also responsible and conscious to weaken the entitlement of poor areas and poor groups to design, focusing on teaching the livelihood skill [22]. Design service is an important form of DPA. Through the "One Village One Product Movement" and the "Hometown-making Movement", Japan has focused its development on the excellent traditional handicraft resources in a certain village or a certain region, and upgraded it to a high-quality brand by using new technologies. The declining rural economy has been recovering through stimulating consumption [23]. The studies on design system pay attention to the sharing platform of information, interaction, benefits and resources among groups in communities $[24,25]$ proposing the social innovation of the integration of decentralized networks, social media, and future cooperation networks, and also proposed that collaboration and localization of design intervention would be most conducive to the flexible development of local culture. With the proliferation of digital technology, handicraft has shifted from materialized levels to dematerialized levels, which is embodied in elements such as relationships and communication. Handicraft design practice can activate the production, marketization and promotion of traditional crafts [26]. Social innovation practice activities provide design services for poor groups through the power of design, and guide the formation of sustainable communities and sustainable lifestyles, providing a new perspective for the development of design disciplines. In the context of social participation, the main actors involved in poverty governance are diversified, including government-led top-level design, grassroots poverty alleviation, and social participation as a supplement and optimization.

\section{Theoretical framework of ANT}

The Actor-Network Theory (ANT) first originated in the fields of science, technology and society is useful for the purpose of this study. One of the core concepts of the theory is the translation between actors. Latour, the original proponent of translation, pointed out that "if the knowledge in the laboratory enters the non-professional residential society and attracts their attention, it must be translated" [27]; Callon proposed to establish a network analysis of human and non-human actors, and at the same time distinguish five keys to translation: problematization, interestement, enrolment, mobilization and dissidence [28]. Among them, problematization means that the actors make the goals problematic; interestement benefit the actors through various strategies so that they can be recruited as network members; mobilization is to form the spokesperson among network members and maintain its operation. In the process, there may be objections that need to be overcome [29]. Callon specifically pointed out that in order for a network of actors to take shape, there must be a common "obligatory passage point" (OPP) among the actors, that is, the consciousness and interests of all actors are successfully brought in to achieve a common direction or goal [28] (Fig. 1).

In the practice of ANT, Secinaro et al. proposed that using actor-netork is benificial to hybrid organizations in managing smart city initiatives [30]. Sage et al. developed ANT concepts and elaborate an affective ANT as an alternative analytical approach to explain the profound role of affects in the circulation of technologies and of technologies in the circulation of affects [31]. David argued that the symmetry principle especially its non-spatial understanding of society in ANT is one tool among others that may benefit the study of digital journalism [32]. In the study of frugal innovation process, Wairokpam extended the usage of ANT and found that frugal innovations are the outcome of negotiations among diverse actors as they attempt to extend their networks and maintain their complex relation during the process of translation [33].

Rural poverty not only refers to economy, but also to the poverty of ability and right. The actor network is not a simple combination of the original actors, but a redefinition of interests, roles, functions and status of them, arranged and endowed in the actor network. Sidorova and Sarker believed that all actors had their own interests and they could persuade other actors to resonate 


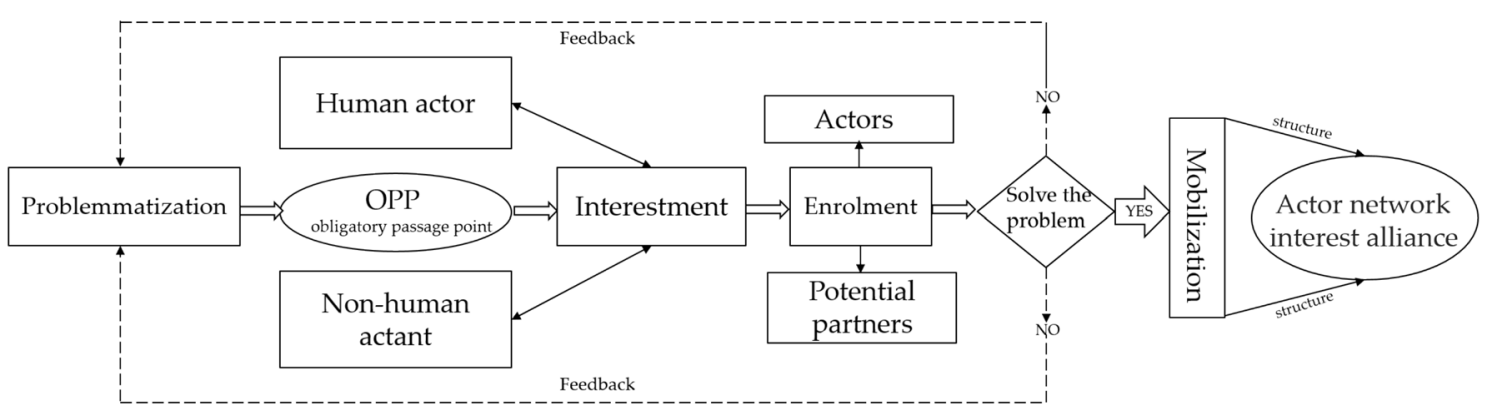

Fig. 1 Actor network and its translation process

with them and form an alliance [34]. Although the ANT theory can describe the translation details of how various actors communicate and reflect dynamic network relationships, it cannot reflect the differences in power between various actors and the limitations of actions caused by social status. Therefore, this article does not copy the ANT completely, but borrows its five translation keys, namely problematization, interestement, enrolment, mobilization and dissidence, to interpret the participatory translation and to describe the specific process of communication among actors.

\section{Methodology}

In this section, Shengzhou bamboo weaving was selected as research object. Utilizing ANT as a fundamental framework to analyze the interest demands of actors related to the process, to construct an actor network of Shengzhou bamboo weaving traditional handicrafts, further, to explore the crucial aspects and core elements for the sustainable development of poverty alleviation design. Finally, the factors influencing this process are evaluated by a questionnaire. Therefore, a combination of quantitative and qualitative methods is used in this study.

\section{The context of study case}

The bamboo weaving craftsmanship plays an important role in the long history of Chinese traditional handicrafts. Shengzhou bamboo weaving with more than 2000 years history was included in China's first batch of national intangible cultural heritage list in 2006. The bamboo industry in Shengzhou includes more than 200 weaving skills and four major technological characteristics: bamboo weaving simulated animals, bamboo silk strip bleaching, strip hot stamping ribs, and blue tire lacquer ware. Bamboo weaving is a delicate handicraft. It takes more than 30 complicated processes from cutting bamboo to the completion. Each process has strict requirements and standards. Shengzhou bamboo weaving are mostly exquisite handicrafts with concrete shapes such as birds and figures, which have high artistic and aesthetic value (Fig. 2).

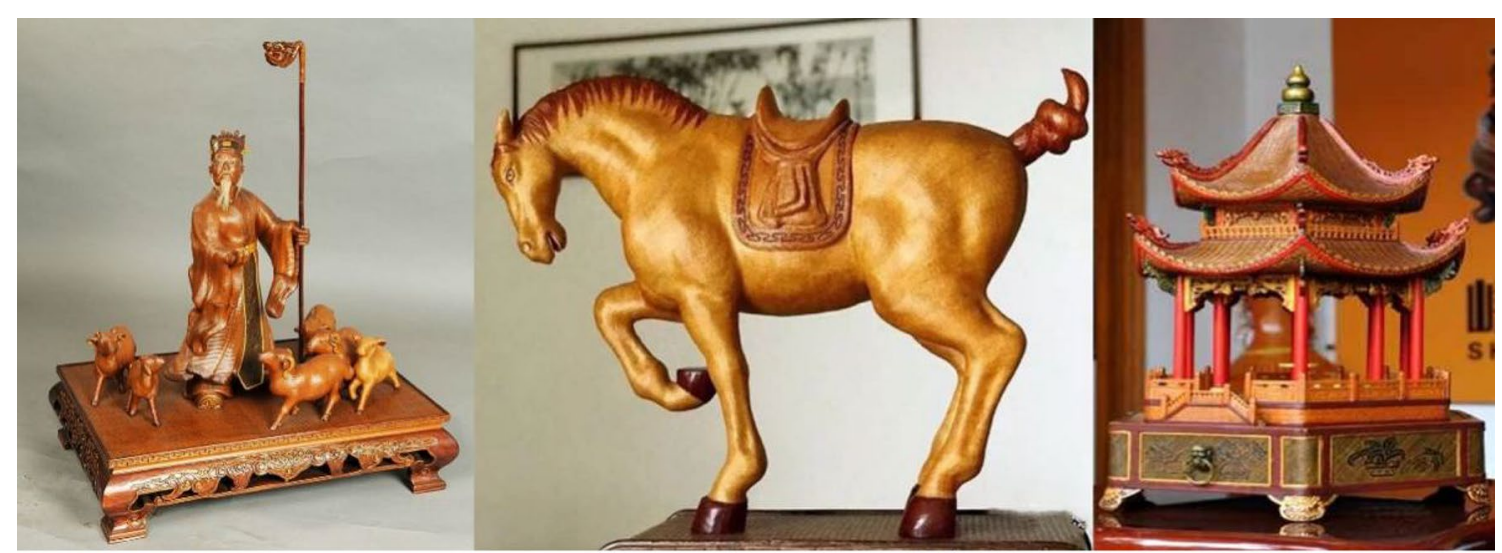

( Photo source: Qianjiang Evening News)

Fig. 2 Exquisite Shengzhou bamboo weaving crafts. (Photo source: Qianjiang Evening News) 
Shengzhou bamboo weaving experienced its peak in 1980s, with more than 3000 employees. By the end of the 1990s, with the impact of plastic products, the demand for bamboo weaving decreased, causing its unprecedented decline. Due to its delicate, rigorous and complicated process and traditional production mode of families and manpower, the productivity of bamboo weaving is quite low. Affected by urban employment demand, the increase in employment channels, and the low daily labor income, the number of bamboo weaving workers has decreased year by year. At present, there are only more than 100 craftsmen in Shengzhou who can independently complete bamboo weaving works. The Shengzhou bamboo industry cannot solve its internal problems through self-regulation, and lacks innovative design, product iterations and experience in industrial resource optimization and regional activation. The support from the government, enterprises, designers and others is needed. As a complex of knowledge, intelligence and information, colleges and universities have significant advantages in design output, talents training, market-oriented competition research, which can give full play to the advantages and cultural and educational attributes of design disciplines. In 2018, the author's team relied on the Shanghai Municipal Education Commission "Folk Art Product Inheritance and Innovation Transformation Studio" to set up a special fund for poverty alleviation and intangible cultural heritage protection, carry out corresponding design and poverty alleviation work.

\section{Design a network of actors for poverty alleviation}

Actors are divided into human actors and non-human actors. Human actors include two categories: inside and outside the community. From the perspective of the main body of social innovation, the main human actors of social innovation can be summarized as: the government, enterprises, designers, farmers and social organizations. In addition, non-human actors are mainly natural and human resources, systems and policies in Shengzhou area. Non-human actants cannot directly express their own interests. They need to construct a diversified, dynamic, and heterogeneous network of time and space through spokespersons and human actors, but their roles in the production of cultural space cannot be ignored (Table 1).

\section{The construction of participatory translation in the actor network}

In the practicalities of the actor network, the "actor" should be the first element, the "handicraft revitalization" as the common goal, the "translation" as the fundamental mechanism, and "problematization" the long-term goal of revitalizing rural handicrafts as the theme of DPA. Then through the stages of "interestement", "enrolment" and "mobilization", the actors are given dynamic meaning, so that the network can operate (Fig. 3).

"Inheriting and promoting bamboo weaving craftsmanship" is an OPP that villagers can put aside their self-interest and work together. The craftsmen face

Table 1 The composition and action goals of the actor network

\begin{tabular}{|c|c|c|c|}
\hline Actors & Categories & Composition & Action goal \\
\hline \multirow[t]{2}{*}{ Human actor } & Inside the rural community & $\begin{array}{l}\text { Village craftsmen, local governments, village } \\
\text { enterprises, villagers' cooperatives, etc. }\end{array}$ & $\begin{array}{l}\text { Protect and inherit cultural values, and increase } \\
\text { economic benefits }\end{array}$ \\
\hline & Outside the rural community & $\begin{array}{l}\text { Design groups, education and training institu- } \\
\text { tions, social organizations, etc. }\end{array}$ & $\begin{array}{l}\text { Provide scientific theoretical guidance and } \\
\text { technical support }\end{array}$ \\
\hline \multirow[t]{2}{*}{ Non-human actant } & Material elements & $\begin{array}{l}\text { Natural resources, human resources, industry } \\
\text { development, skills, etc. }\end{array}$ & $\begin{array}{l}\text { Protect and inherit intangible cultural heritage in } \\
\text { rural areas }\end{array}$ \\
\hline & Non-material elements & $\begin{array}{l}\text { Daily life, funds, policies, relevant laws and } \\
\text { regulations, information, etc. }\end{array}$ & $\begin{array}{l}\text { Create a good rural handicraft cultural environ- } \\
\text { ment }\end{array}$ \\
\hline
\end{tabular}

Craftsmen: Craftsmen are the largest group in the actor network of DPA, the core actors in rural construction, the objects of rights and information, and the groups most directly affected by poverty alleviation actions. Their appeal is to increase income and improve the life quality by making, producing various bamboo woven products

Design group: It is the coordinator of the network of DPA, with professional design knowledge and vocational skills. It can become a communication bridge among the government, craftsmen and other actors in the DPA process, coordinate the interests of various actors, provide technical support for handicraft design, and enhance the villagers' self-governance awareness and realize their own value by the combination of theory and practice

Village enterprise: It is the supporter of the action network, which realizes participation by providing production technology and commercial services. It obtains profit through investment and maximizs public interests

Villagers' cooperatives: They are participants in the action network, and provide employment opportunities for villagers through mutual economic organizations established through the cooperation of similar handicrafts

Local government: It usually plays the leader in the actors network and the representative of public interests, realizing the overall development of urban and rural areas and promoting local social, economic and cultural development and the formulation and implementation of related policies

Social organization: It is an assistant to the actors network. Since social organizations are independent of the government and the market, they play a positive role in making up for the lack of the main body of public welfare social affairs in rural areas. It provides assistance in training and funding for rural construction, promoting rural development and enhancing the quality of villagers 


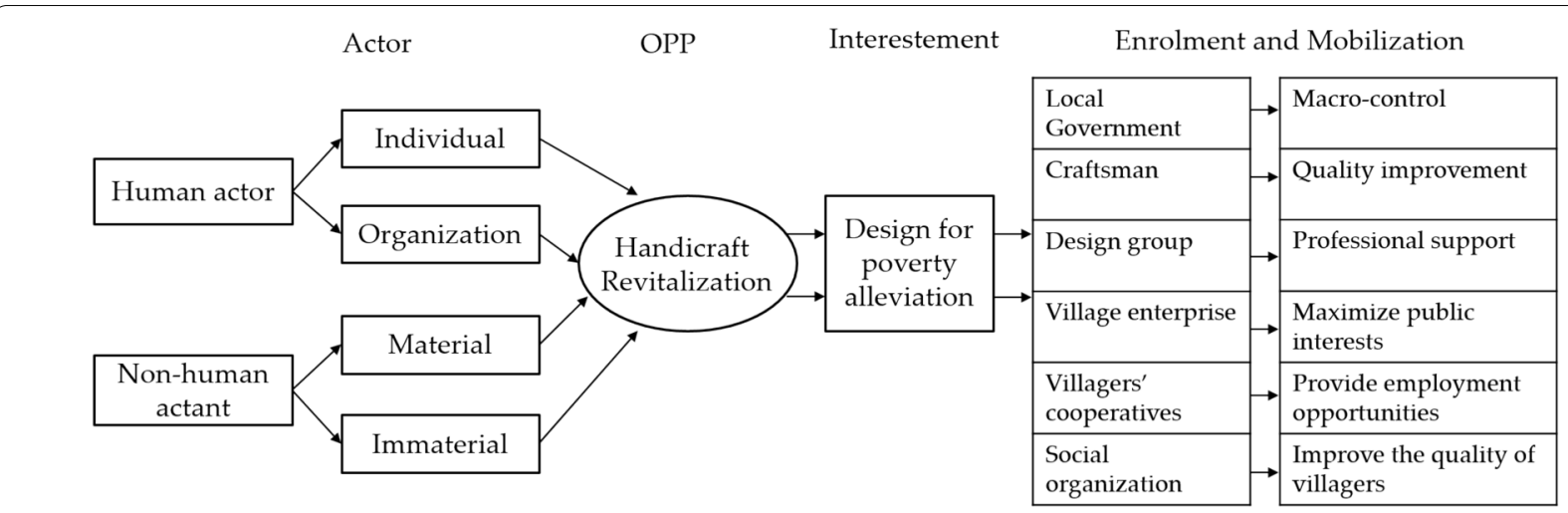

Fig. 3 Operating mechanism of the acting network

problems such as low income, moving out for work, and low participation; the government faces problems like the imbalance of urban and rural development, serious brain drain in rural areas, and uncoordinated industrial development; designers and social organizations, as outsiders, face the lack of villagers' trust and understanding of handicraft skills; Villagers' cooperatives are faced with issues like the loss of manpower, the responsibility of integrating the interests of craftsmen and capital input and output. Investigate the interests of the poor and other subjects, establish a meeting point for all stakeholders. By connecting the OPP of multiple social actors, we can clarify the consensus hub that can involve all actors. Comprehensively, we believe that DPA needs to solve four problems: cultural creativity, industrial development, cultural conservation, and social relations (Fig. 4), including inheritance and promotion of handicrafts, development of bamboo weaving industry, and sustainability of knowledge and social relations.

The research of Callon and Latour pointed out that only sufficient mobilization and gathering can form a successful actors network [35-37]. The design team understands the basic interest of the village and the interest needs of craftsmen through village site surveys, household interviews and group meetings. In this process, by buiding trust with craftsmen, we can get a deeper understanding of the local social ecology, further clarify problem definitions, and build universal recognition of a consensus hub. Through the participatory workshops sharing power and responsibility and the identity construction of the consensus hub, it further recruited and mobilized a group of rural craftsmen who mainly inherited local culture, expanded the alliance of interests involved in translation, and connected the vision of outsiders with local resources to promote the formation of a social network. Designers play a guiding role in the process of integrating and deploying resources. Aiming at the issues of cultural creativity, industrial development, cultural conservation, and social relations, a multiple actors participation network that values the initiative and interests of craftsmen is established (Fig. 5).

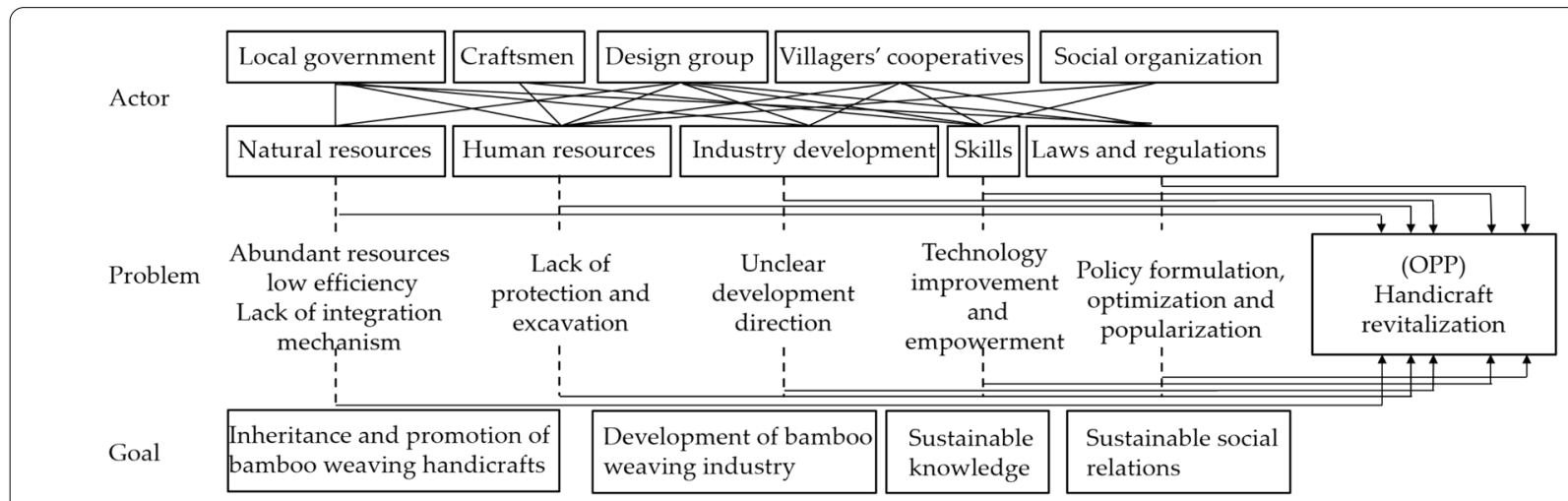

Fig. 4 Design of obligatory access points and consensus hubs for poverty alleviation 

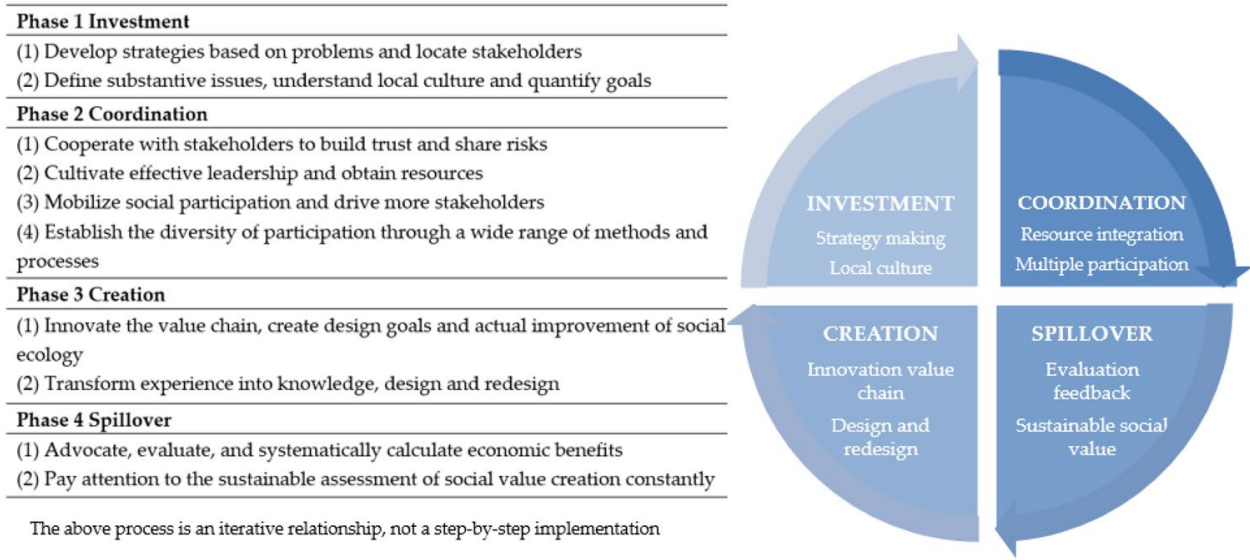

Fig. 5 Designing the action participation process for poverty alleviation

\section{Cultural and creative level}

The original daily life value of bamboo weaving is weakening. The design team tries to understand and verify the different needs of craftsmen with empathy and their ability, motivation to participate in social innovation, pays attention to social needs, and understands their local knowledge. In this process, the designer analyzes the stakeholders, sorts out the local social relations and value system, and draws a map of rural bamboo cultural assets by collecting materials, technology, craftsmanship, structure, color, and aesthetic symbols. Through guided design interventions, such as case sharing of regional culture driving local development, and organization of community activities such as workshops, we interview with handicraftsmen and village committees, understand the needs and ideas of craftsmen and local villagers, and analyze the current situation in the village and the reasons for the industrial decline, then putting forward new design ideas through cultural probes [38] and bodystorming [39] (Fig. 6).

The fundamental reason for the decline of bamboo weaving is that the works are too traditional and lack in variation which have lost the survival and development space in modern society. The designers connect the vision of outsiders and local resources to promote the formation of a creative community network for the productive protection of practical bamboo weaving, and to reshape the design concept and aesthetic consciousness of bamboo weaving products. The design team uses the Zaltman metaphor elicitation technique (ZMET) to carry out design model planning, and extracts the "ingenuity", "inheritance", "environmental protection", "elegance", "exquisiteness" and "Chinese aesthetics". Implanting modern design into traditional techniques, the living rheology should not just remain conservative in the storage and inheritance of the old culture, but combining with

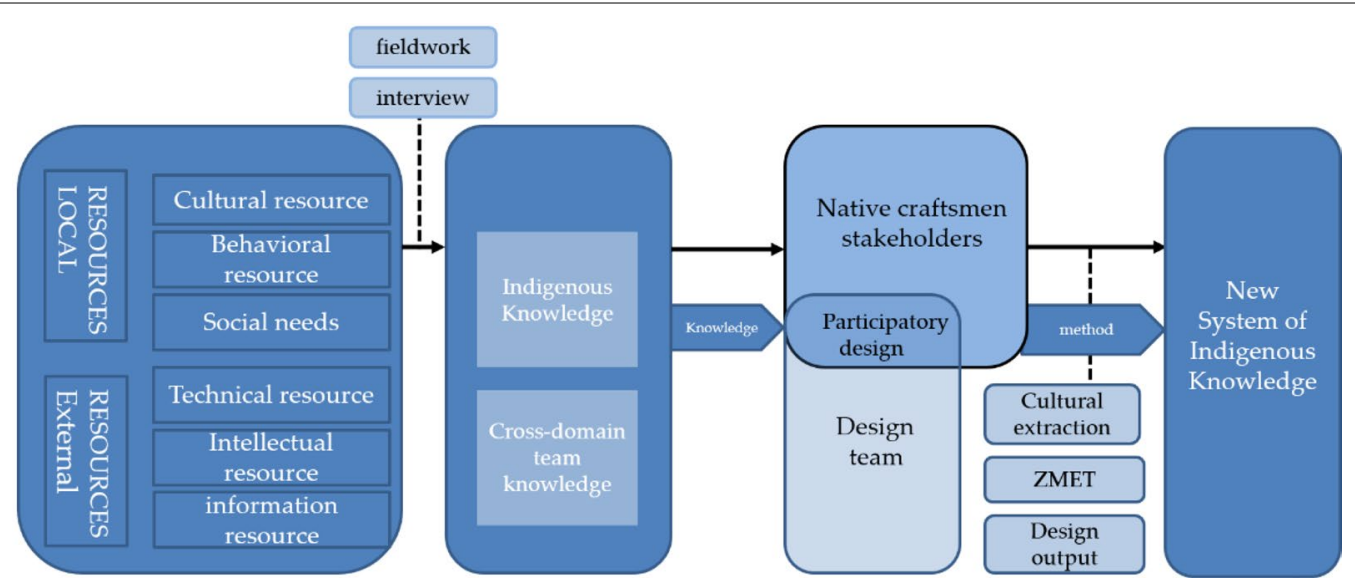

Fig. 6 Construction process of participatory design 
the contemporary background of cultural innovation and economic development, they return to daily lives with a new attitude in the process of merging and deconstructing the inherited national emotions and spirits, so as to realize the connection between traditional bamboo weaving and modern life demand.

Industry level Chinese villages are in a dual society that is transforming from tradition to modernity which prompted the team to develop DPA with innovative ideas and modern industrial thinking. By using the Leaping Frog Thinking, the overlooked opportunities are discovered to achieve reversal and reverse transcendence. Technically, we carried out improved designs on the basis of maintaining its core technical characteristics, and it is not necessary to use traditional methods completely in the production to achieve a balance of cost and profit. Functionally, it has changed from focusing on decoration to practicality. Through the combination of bamboo laminated timber, bamboo reconstituted timber and bamboo weaving, the high-efficiency molds are partial used to achieve partial industrialization, and modular system design methods are adopted to improve manufacturing accuracy and efficiency. With the combination of modern production and traditional manual production, the Shengzhou bamboo weaving has embark on the road of industrialization.

Based on the combing of business content and model construction, the category is vertically subdivided to establish a branded product portfolio, realizing the indepth market positioning of cutting-edge art of high-end customized products, diversification of modern customized products, personalized and fashionable daily products, and high-quality intangible heritage products. Among them, intangible cultural heritage products are developed based on the need of handicraft inheritance, derivative products appropriately use technology means to realize creative development and form an innovative industrial chain that combines handicraft culture retention, partial industrial production, and modern commercial operations. Conduct exploratory research on consumers, combine fine catering, tea ceremony and tea sets, develop specialty products, and increase the social supply of intangible cultural heritage products (Fig. 7). In this process, Large-scale villagers' cooperatives help to attract more craftsmen and local villagers to participate in. Different craftsmen are responsible for different production links, which can guarantee the quality more effectively. The local rural service industry structures interests through the form of cooperatives, effectively avoiding vicious competition within the village. Through the government's policy guidance, active participation with social organizations, and effective support in terms of talents, capital, technology, etc., Shengzhou Bamboo Weaving has improved in its competitiveness, production scale and diversity.

Cultural preservation level The core of DPA is not poverty but people. In the rural areas, the insufficient public services and other reasons results in the long-term backward. At the level of cultural preservation, it is necessary to fully mobilize the government, universities, research institutes, enterprises, and local elites including representative inheritors and community craftsmen to carry out extensive collaboration. With the help of the "China

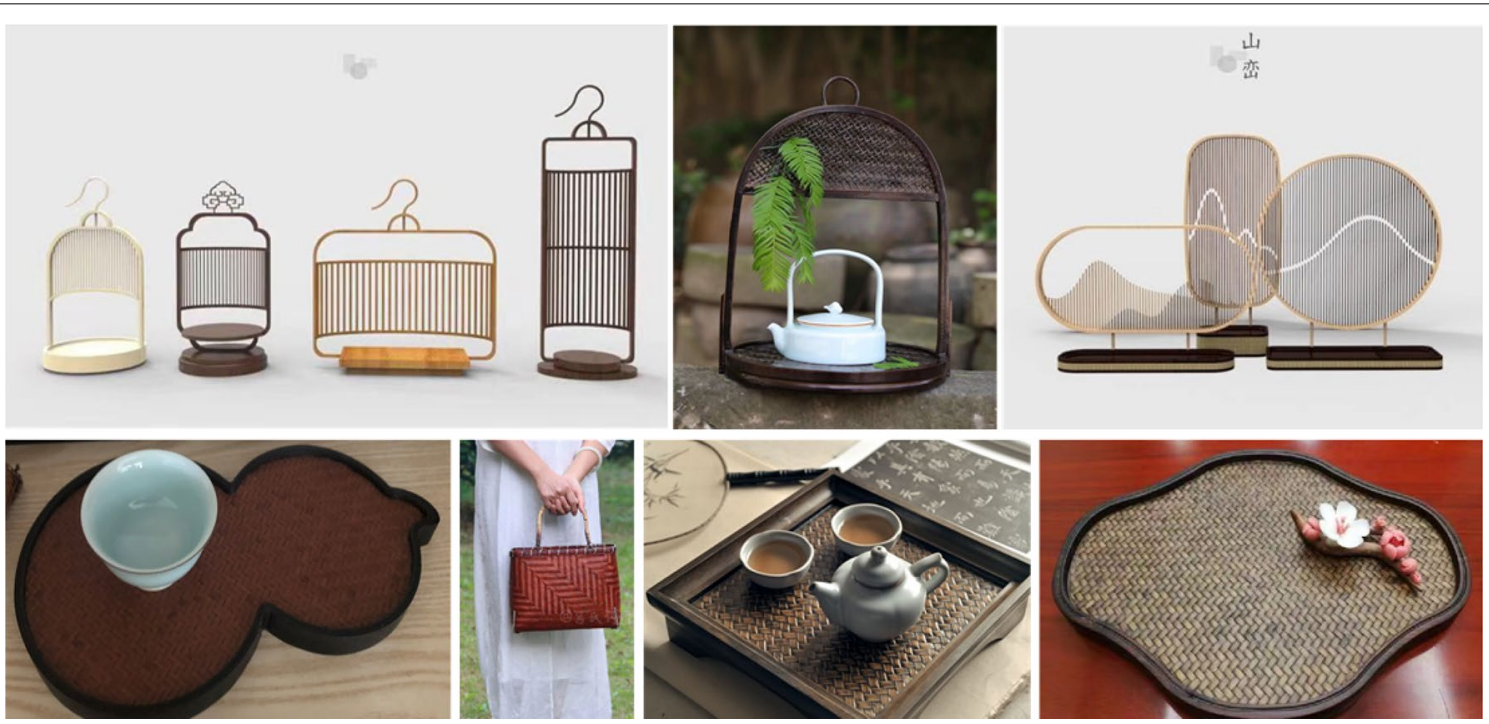

Fig. 7 Innovative Shengzhou bamboo weaving industry and product types 
Intangible Cultural Heritage Inheritance Crowd Research and Training Program" initiated by the state, the National Art Fund Talent Training Program,, the Shengzhou region promotes the cooperation between craftsmen and universities to offer culturally characteristic courses and invite experts to give lectures, creating a shared and open learning environment and guiding the poor to learn intangible cultural heritage skills in various ways. A series of training to convey the quality and value of regional cultural assets can strengthen non-academic education and skills training for non-genetic inheritors.

In this process, local governments are the main body of the recruitment, and all actors are given acceptable tasks. Local craftsmen participate in training under the mobilization of local governments to increase the proportion of beneficiaries of the research and training program and expand their external channels and opportunities for communication and display. By developing wisdom of crowds, creative communities for poverty alleviation are built and designed. It is easier to spread and continue rural culture and local skills and knowledge. College designers and interdisciplinary teams integrate into the community to produce practical solutions in collaboration with craftsmen, and expand their influences both inside and outside the community, thereby attracting more members and resources to flow in, and then activating the aesthetic capabilities and creativity, participation and cohesion. The sustainability of folk handicrafts is ultimately to empower the handicraft inheritors with ability of inheritance and innovation, so that they can quickly realize the transition from imitation to innovation, and from being assisted to independent innovation.

Social relationship level During designers' intervene in the design and development of local handicrafts, the output is the specific design and the new production organization relationship. It can be regarded as a process of reorganizing the traditional value system and culture [40]. The quality of rural community relationship means that the relationship capital generated by the "supportive economy" in the DPA must be fully paid attention to the sharing and interaction of information, resources, and interests among stakeholders.

The DPA team takes full consideration of rural-social relations and builds a three-level network of design, innovation and social to achieve enhanced community resilience and effective incentives, strengthen the guidance and unity between craftsmen' cooperatives, enhance the sense of identity, communication and happiness. The design team uses bottom-up approach to promote the ability of local cooperation by activating the participation mechanism of different roles in the process of DPA, so that participants become active solvers of their own problems. The process of DPA projects first determines the rural talents and craftsmen, and the design team and the local craftsmen establish a peer-to-peer partnership. By co-creating various cultural activities with social organizations, it can change the social activities and interaction methods in the past, which are mainly based on blood relationships, re-establishes the cultural connection structure between people in the village, and facilitates conversations among community members and sharing of useful information. With the help of rural talents and non-genetic inheritors, they will become the think tank of the village, which will stimulate the imitation and participation of other craftsmen, thereby forming a point-to-face effect, rapidly developing community productivity, expanding their influence, and driving more people toward the path of common prosperity.

\section{Dissent and resolution}

Dissent is a connection of resistance, friction and conflict, which shows that the conflicting interests of actors will cause dynamic changes in the network. The construction of the actor network is a process of dynamic change. Along with changes in interest demands, actors continue to join or withdraw, and core actors play an irreplaceable role in the establishment and update of the network. The dissent in this course focuses on the long-term and short-term interests of the protection and inheritance of the local handicrafts in Shengzhou, the integrated operation of the handicrafts brand and the imbalance of the interest pattern. If there is a serious exploitation of the surplus value of the craftsmen in the production, they will encounter resistance in the form of resignations and strikes by the craftsmen. In the process of tapping the value of the intangible heritage handicraft industry, we must stick to the bottom line of handicraft protection. The premise of keeping the bottom line is make clear what should be kept and what can be innovated, avoiding shallow utilization and development of intangible cultural heritage handicrafts with quick success and instant benefits, avoiding being overly kidnapped by short-term economic goals, and finally conducting unilateral and paranoid development that violates the law of development.

\section{Social impact analysis of design for poverty alleviation}

After the end of two-year project, the research team verified and explained the effectiveness of the DPA through reflection, and conducted a questionnaire survey for the poverty alleviation subjects by random sampling. The questionnaire is divided into two parts, the first part is about the basic information, including gender, age, education, income, etc.; the second part is the subjective cognition part, which mainly inquires about the subjective 
reaction and attitude of the local craftsmen (Table 2). All test structures were measured using the 5-point Likert scale. Likert scale is a tool to measure attitude, which has had a great impact on the field of social science since it was proposed. Likert scale ranges from "strongly disagree" to "strongly agree", namely 1 for strongly disagree, 2 for disagree, 3 for not sure, 4 for agree, and 5 for strongly agree [41]. The score of the questionnaires were expressed as mean and sample standard deviation (SD). For the low scoring results, less than 3 (disagree), regression analysis is used to explore the associated sociological characteristics. Since the dependent variables are ordered multi classification variables (Likert score results), and the level of variables is more than 2, the Multiple Ordered Logistic Regression is used [42-44]. In this process, the univariate test was used to determine which variables are significant as a form of screening and rejected the majority of variables where $\mathrm{P}>0.05$, retaining variables are entered into multivariate test to identify the significant factors effect these low scores. The univariate models are $y=b_{0}+b x$, whereas the multivariate models are $y=b_{0}+b_{1} x_{1}+b_{2} x_{2}+\ldots . . b_{k} x_{k}+u$. The squared or interaction terms are not included in this test. The odds ratio (OR) [45] in logistic regression represents the effect of a variable, on the possibility that one outcome will occur. The confidence interval (CI) was used to estimate the range of overall parameters with $95 \%$ probability [45]. A $\mathrm{P}<0.05$ was considered statistically significant.
Descriptive statistics and all calculations were performed for the study variables using the IBM SPSS Statistics for Windows, Version 26 (IBM Corporation Armonk, NY, USA).

\section{Results and discussion}

Questionnaires were distributed to 50 Shengzhou craftsmen, and resulted in 32 valid questionnaires return (64\%). It is shown in Table 3 that $96 \%$ of the interviewees were local people, and only 3 were immigrants. This fact is closely related to the family-style inheritance of handicrafts that mainly relies on oral teaching. The average age of the population is 53.2 years, of which the 46-65 age group accounts for the majority of $77.4 \%, 1$ person under 25 years old, and 2 people over 65 years old. They tend to be elder in age and low in education level. Most respondents $(68.8 \%)$ had high school education or below, and $31.2 \%$ of those received technical school and undergraduate education. Twenty-five respondents had a monthly income of less than RMB 5000, 7 people had a monthly income of more than RMB 5000, and 2 people had a monthly income of more than RMB 10,000. About one-third of the respondents (37.5\%) have received different forms of skills training, while the remaining craftsmen did not participate.

Respondents are basically positive about the impact of design intervention on cultural creativity and industrial development, with an average score of 4 or more

Table 2 Indicators of the questionnaires

\begin{tabular}{llll}
\hline Indicators & Sub-indicators & Indicators & Sub-indicators \\
\hline Cultural and creative level & $\begin{array}{l}\text { The quality of bamboo weaving design } \\
\text { The development needs of the times } \\
\text { Protection and inheritance of handicrafts }\end{array}$ & Cultural preservation level & $\begin{array}{l}\text { Design skills } \\
\text { Industrial development level }\end{array}$ \\
& Economic income of craftsmen & Diver cultural activities \\
& Bamboo Weaving Related Industry Development \\
& Local regional economic development & Social relationship level & Motivation and participation \\
& & Job opportunity \\
& & Community cultural identity
\end{tabular}

Table 3 Characteristics of the interviewees

\begin{tabular}{|c|c|c|c|c|c|c|c|}
\hline Item & Demographics & $\begin{array}{l}\text { Number of } \\
\text { respondents }\end{array}$ & Percentage & Item & Demographics & $\begin{array}{l}\text { Number of } \\
\text { respondents }\end{array}$ & Percentage \\
\hline \multirow[t]{4}{*}{ Age } & $<25$ & 1 & 3.1 & Education level & $<$ High school & 22 & 68.8 \\
\hline & $25-45$ & 5 & 15.6 & & Vocational education & 8 & 25.0 \\
\hline & $46-65$ & 24 & 77.4 & & $\geq$ Undergraduate & 2 & 6.2 \\
\hline & $>65$ & 2 & 6.2 & Monthly income ( $¥)$ & $<3000$ & 4 & 12.5 \\
\hline \multirow[t]{2}{*}{ Gender } & Male & 14 & 43.8 & & $3000-5000$ & 21 & 65.6 \\
\hline & Female & 18 & 56.2 & & $5001-10,000$ & 5 & 15.6 \\
\hline \multirow[t]{2}{*}{ Local Resident } & Yes & 29 & 90.6 & & $>10,000$ & 2 & 6.3 \\
\hline & No & 3 & 9.4 & Train & Yes/no & $12 / 20$ & $37.5 / 62.5$ \\
\hline
\end{tabular}


(Table 4). In 6 index questions, the minimum personal score is 3 points, which is basically recognized, and the maximum standard deviation is 0.70 . In the cultural conservation and social relations levels, there are indicators below 3 (not recognized). They are "improving design skills" with 2.93 points and "enhancement of participation" with 2.62 points, and there is a minimum score of 0 points. The highest score in the "enhanced social participation" indicator is 4 points, which is the only indicator that does not receive full score among all 12 indicators. The standard deviations of the two indicators are 1.35 and 1.34, respectively, reflecting that the respondents have opposing evaluations in the evaluation of these two indicators.

Aiming at the low score of "design skills improvement" and "enthusiasm and participation" in the abovementioned 12 indicator systems, we conducted a logistic regression of these 2 score results to explore the associated sociological characteristics. As the demographic showed in Table 3, most of the interviewees in this study are local residents $(29 / 32,90.6 \%)$ and over 45 years (26/32, 83.6\%), only one under 25 years old. So, in our univariate test we found some enormous range of $\mathrm{CI}$ (confidence interval), like age in Table 5, age and local resident in Table 6. Especially in Table 6 the "infinite" range of confidence intervals all correspond to $\mathrm{P}=0.999$, so there is no significance in these factors (age, local resident). Basically, they have no correlation with the characteristics and should not be included in the multivariate models. In Table 5, univariate analysis shows that age, education, prior training are factors associated with the low score of "design skills improvement". Multivariate analysis demonstrated the prior training (OR 0.004 $95 \% \mathrm{CI}<0.001,0.121 \mathrm{P}<0.05)$ to be significant factor for the low score. The results in Table 6 suggest that in the "enhancement of social participation" indicator, univariate analysis shows that education and prior training are factors associated with the low score. Multivariate analysis demonstrated that only the level of education (OR $0.01495 \% \mathrm{CI} 0.001,0.178 \mathrm{P}=0.001$ ) is the significant factor.

Rural communities are the combination of continuous production and reproduction of material space and sophisticated social relations. ANT provides a new perspective on design interventions by building relationships between actors in a structured way and by incorporating elemental flows and interaction patterns into the analysis. The actor network led by the designer is an innovative, implemented and associative restructuring of approaches since the actors themselves have structural elements such as functions and effects. Therefore, by analyzing actors who are put in the background of rural social network, we can accurately find the action ideas, methods and results of DPA. Since the existence of heterogeneous actors in rural communities, the results of poverty alleviation may be one-sided no matter in view of human needs or the functionality of objects. ANT provides a research lens to understand the mutual relation between actor and actant. The network containing heterogeneous actors based on ANT will assist exerting actors' subjective initiative. Under the circumstances, not only the construction of actor networks is influenced, but actors' subject positions and power can be reframed, which provides a more comprehensive, systematic and holistic recognition of the actors' network in DPA.

The benefit of the poor people is not only reflected in the economy, but also reflected in the reshaping of personal achievements and social relations, showing a diversified benefit aspect in the DPA. On the one hand, craftsmen have improved their income and living quality,

Table 4 Interviewees' impressions of craft design

\begin{tabular}{|c|c|c|c|c|c|}
\hline Indicators & Sub-indicators & Question & Mean & Score range & SD \\
\hline \multirow[t]{3}{*}{ Cultural and creative level } & The quality of Bamboo weaving design & Q1 & 4.59 & $3-5$ & 0.37 \\
\hline & The development needs of the times & Q2 & 4.00 & $3-5$ & 0.45 \\
\hline & Protection and inheritance of handicrafts & Q3 & 4.06 & $3-5$ & 0.51 \\
\hline \multirow[t]{3}{*}{ Industrial development level } & Economic income of artisans & Q4 & 4.68 & $4-5$ & 0.14 \\
\hline & Bamboo weaving related industry development & Q5 & 3.94 & $3-5$ & 0.70 \\
\hline & Local regional economic development & Q6 & 4.03 & $3-5$ & 0.42 \\
\hline \multirow[t]{3}{*}{ Cultural preservation } & Design skills improvement & Q7 & 2.93 & $0-5$ & 1.35 \\
\hline & Diversity of cultural activities & Q8 & 3.84 & $3-5$ & 0.39 \\
\hline & External cultural exchange channels & Q9 & 4.18 & $4-5$ & 0.16 \\
\hline \multirow[t]{3}{*}{ Social relationship level } & Enhancement of participation & Q10 & 2.62 & $0-4$ & 1.34 \\
\hline & Job opportunity & Q11 & 4.09 & $4-5$ & 0.08 \\
\hline & Community cultural identity & Q12 & 3.87 & $3-5$ & 0.43 \\
\hline
\end{tabular}


Table 5 Logistic regression analysis of characteristic associated with design skills improvement

\begin{tabular}{|c|c|c|c|c|}
\hline \multirow[t]{2}{*}{ Characteristic } & \multicolumn{2}{|l|}{ Univariate } & \multicolumn{2}{|l|}{ Multivariate } \\
\hline & OR $(95 \% \mathrm{Cl})$ & $\mathbf{P}$ & OR $(95 \% \mathrm{Cl})$ & $\mathbf{P}$ \\
\hline Age & $11.482(1.258,104.776)$ & 0.030 & $6.893(0.704,67.527)$ & 0.097 \\
\hline \multicolumn{5}{|l|}{$<25$} \\
\hline \multicolumn{5}{|l|}{$25-45$} \\
\hline \multicolumn{5}{|l|}{$46-65$} \\
\hline \multicolumn{5}{|l|}{$>65$} \\
\hline Gender & $1.145(0.270,4.867)$ & 0.854 & & \\
\hline \multicolumn{5}{|l|}{ Male } \\
\hline \multicolumn{5}{|l|}{ Female } \\
\hline Local resident & $3.800(0.306,47.211)$ & 0.299 & & \\
\hline \multicolumn{5}{|l|}{ Yes } \\
\hline \multicolumn{5}{|l|}{ No } \\
\hline Education & $0.022(0.002,0.244)$ & 0.002 & $2.234(0.943,10.352)$ & 0.742 \\
\hline \multicolumn{5}{|l|}{$<$ High school } \\
\hline \multicolumn{5}{|c|}{ Vocational education } \\
\hline \multicolumn{5}{|l|}{$\geq$ Undergraduate } \\
\hline Monthly income (¥) & $0.286(0.074,1.108)$ & 0.070 & & \\
\hline \multicolumn{5}{|l|}{$>3000$} \\
\hline \multicolumn{5}{|l|}{$3000-5000$} \\
\hline \multicolumn{5}{|l|}{$5000-10,000$} \\
\hline \multicolumn{5}{|l|}{$>10,000$} \\
\hline Prior training & $0.005(<0.001,0.084)$ & $<0.001$ & $0.004(<0.001,0.121)$ & 0.002 \\
\hline \multicolumn{5}{|l|}{ Yes } \\
\hline No & & & & \\
\hline
\end{tabular}

and to a certain extent also strengthened their cultural conservation and cultural identity. On the other hand, DPA also focuses on non-economic benefits. Through design empowerment, the subjectivity of craftsmen can be played, and to a certain extent their visibility and participation in poverty alleviation and their ability to resist risks can be improved.

Poverty alleviation information is affected by actual conditions such as the education, age, and their receptivity. Whether to improve design skills is mainly affected by age and participation in training. The average age of bamboo weaving craftsmen is over 50 years. The overall staff is aging and the level of knowledge is not high. The ideology is more traditional and conservative. They tend to be content with customs. Although they have the desire to escape poverty, the achievement motivation value is not high, and they are used to passively accept external information. Only about one-third of the respondents (37.5\%) have received different forms of skills training, while the remaining craftsmen did not participate. When asked "what are the shortcomings of the design in the process of intervention", the respondents thought that the existing designing poverty alleviation was "impractical" and "difficult to operate" and held a conservative tendency toward the new ideas. In the protection of rural handicrafts and targeted poverty alleviation, the poor can obtain sustainable economic benefits, but their participation is low, and they are only the seller of labor. In DPA process, craftsmen are often passive and silent, lacking channels and communication opportunities to express their wishes, so that their true feelings and situations cannot be presented and their subjectivity cannot be demonstrated. Therefore, barriers to knowledge acceptance hinders the development of the craftsman's subjectivity. It can be seen that it takes longer to achieve the goals of respecting the subject status of poverty alleviation targets and community empowerment.

The enhancement of social participation, is affected by the craftsmen's education level. That people with lower education level tend to use social relationships such as blood and kinship to make decisions. Those with higher levels of education tend to seek decision support and help through more types of relationships when making decisions, such as karmic connection and friendship. The existing villages in China still use the social relationship of the circle attribute of relatives and acquaintances, and the traditional characteristics of the social structure are still very obvious. In the production process, information 
Table 6 Logistic regression analysis of characteristic associated with enhancement of participation

\begin{tabular}{|c|c|c|c|c|}
\hline \multirow[t]{2}{*}{ Characteristic } & \multicolumn{2}{|l|}{ Univariate } & \multicolumn{2}{|l|}{ Multivariate } \\
\hline & OR $(95 \% \mathrm{Cl})$ & $\mathbf{P}$ & OR $(95 \% \mathrm{Cl})$ & $\mathbf{P}$ \\
\hline Age & $1.3^{*} 10^{8}(0,+\infty)$ & 0.999 & & \\
\hline \multicolumn{5}{|l|}{$<25$} \\
\hline \multicolumn{5}{|l|}{$25-45$} \\
\hline \multicolumn{5}{|l|}{$46-65$} \\
\hline \multicolumn{5}{|l|}{$>65$} \\
\hline Gender & $0.513(0.117,2.248)$ & 0.376 & & \\
\hline \multicolumn{5}{|l|}{ Male } \\
\hline \multicolumn{5}{|l|}{ Female } \\
\hline Local resident & $4.2^{*} 10^{8}(0,+\infty)$ & 0.999 & & \\
\hline \multicolumn{5}{|l|}{ Yes } \\
\hline \multicolumn{5}{|l|}{ No } \\
\hline Education & $0.014(0.001,0.178)$ & 0.001 & $0.006(<0.001,0.132)$ & 0.002 \\
\hline \multicolumn{5}{|l|}{$<$ High school } \\
\hline \multicolumn{5}{|c|}{ Vocational education } \\
\hline \multicolumn{5}{|l|}{$\geq$ Undergraduate } \\
\hline Monthly income (¥) & $0.405(0.118,1.392)$ & 0.151 & & \\
\hline \multicolumn{5}{|l|}{$>3000$} \\
\hline \multicolumn{5}{|l|}{$3000-5000$} \\
\hline \multicolumn{5}{|l|}{$5000-10,000$} \\
\hline \multicolumn{5}{|l|}{$>10,000$} \\
\hline Prior training & $0.037(0.005,0.263)$ & 0.001 & $1.251(0.621,4.887)$ & 0.231 \\
\hline \multicolumn{5}{|l|}{ Yes } \\
\hline No & & & & \\
\hline
\end{tabular}

is often obtained through acquaintance. Only after the acquaintance is successful, will they transform the role of onlookers to follow suit. Prior to this, they have always been cautious on the sidelines. Design intervention cannot only be the top-down giving and passive acceptance with craftsmen. It is necessary to cultivate new social relationships and fully establish interpersonal relationships with trust as the bond.

In prior research, the studies on 'Translation', a key term in ANT, only limited to the level of conceptual exploration but lacking of case verification. This study provides a comprehensive and in-depth interpretation of this key term, among which, the kernel of ANT was drawn closer and relevant strategies provided for poverty alleviation design were accordingly developed.

\section{Conclusions}

Facing the complex problems of Chinese rural construction, a flexible and structured form is needed to build a cultural community between the city and the country, and a positive interaction with culture as the core is gradually developed between the country and the city. DPA is not just a design proposal, but an integrated thinker who can intervene in the implementation of the solution strategy. This study incorporates the concept of sustainable development into the handicraft inheritance, advocates the return of folk handicrafts to daily life with the concept of systematic innovation, and continuously promotes the comprehensiveness from handicraft inheritance to knowledge innovation, from craftsmanship to technological innovation, from traditional reconstruction to life innovation practice, etc. From the awareness of ecological crisis, we deeply reflect on the inherent logic and realistic conditions of China's non-inherited inheritance, in order to explore a development model that takes into account the continuous progress of social economy and the coexistence of cultural expression in the context of globalization.

Any tradition will be invalid if it is not activated by the social reality structure. Design intervention makes the design participate in the social innovation of rural handicraft traditions in a more tense structure. In this research, various actors are connected with each other through issues such as problem presentation, benefit granting, recruitment and mobilization, and dissent. They form an actor network for the development of the national traditional handicraft industrialization of Shengzhou Intangible Heritage. Design is not all-inclusive, but 
to optimize and link different action systems, create an inclusive participation environment and social relations, achieve a balance between the capabilities and willingness of participants, and strive to restore the constantly changing productive cycle system of intangible cultural heritage, gradually forming a mature and complete cooperation model.

\section{Limitations and future research}

Design for Poverty Alleviation is a dynamic process which, from ANT perspective, requires continuous observation and updating, as well as supplementing and improving its problems and deficiencies of the last phase in order to stabilize the actor network of rural communities. The problems and challenges which poverty alleviation design facing are diverse and constantly renewed. The great diversity exists among Chinese rural areas in rural specialties, industrial characteristics, history and culture respectively. Along with expansion of material consciousness and constant enhancement of social network in the process of rural construction, we naturally argue that the network construction is not static, within which the trend of changes, the core values of central actors and aesthetic trends are constantly evolving. Therefore, it is necessary to make further exploration and research on usage scope, methodology, key elements network size controlling and roles selecting of theory.

The long-term involvement of professional design teams in rural local communities is not a final solution. These issues of when to withdraw from rural traditional communities, how to maintain proper contact with community residents, and how to finally enable local community residents to create local windows with a more independent and confident attitude, and actively inheriting and developing the cultural heritage of the nation in the context of modernization and globalization, have always existed in social innovation and they are worthy of continued exploration and research in practice.

\section{Appendix A: Questionnaire on attitude}

\begin{tabular}{|c|c|c|c|c|c|c|}
\hline \multirow[t]{2}{*}{ Indicators } & \multirow[t]{2}{*}{ Questions } & \multicolumn{5}{|l|}{ Attitude } \\
\hline & & Fully agreed & agreed & General & Disagreed & Fully disagreed \\
\hline \multirow[t]{3}{*}{$\begin{array}{l}\text { Cultural and creative } \\
\text { level }\end{array}$} & $\begin{array}{l}\text { Q1 Do you think the } \\
\text { design team has } \\
\text { helped improve the } \\
\text { quality of bamboo } \\
\text { weaving design? }\end{array}$ & & & & & \\
\hline & $\begin{array}{l}\text { Q2 Do you think the } \\
\text { new design meets the } \\
\text { needs of the develop- } \\
\text { ment of the times? }\end{array}$ & & & & & \\
\hline & $\begin{array}{l}\text { Q3 Do you think the } \\
\text { new design is benefi- } \\
\text { cial to the protection } \\
\text { and inheritance of } \\
\text { bamboo weaving } \\
\text { craftsmanship? }\end{array}$ & & & & & \\
\hline \multirow[t]{3}{*}{$\begin{array}{l}\text { Industrial develop- } \\
\text { ment level }\end{array}$} & $\begin{array}{l}\text { Q4 Do you think the } \\
\text { income of craftsmen } \\
\text { has increased after } \\
\text { design intervention? }\end{array}$ & & & & & \\
\hline & $\begin{array}{l}\text { Q5 Do you think } \\
\text { design intervention } \\
\text { will help the develop- } \\
\text { ment of the bamboo } \\
\text { weaving industry? }\end{array}$ & & & & & \\
\hline & $\begin{array}{l}\text { Q6 Do you think that } \\
\text { design intervention } \\
\text { will help local rural } \\
\text { economic develop- } \\
\text { ment? }\end{array}$ & & & & & \\
\hline
\end{tabular}




\begin{tabular}{|c|c|c|c|c|c|c|}
\hline \multirow[t]{2}{*}{ Indicators } & \multirow[t]{2}{*}{ Questions } & \multicolumn{5}{|l|}{ Attitude } \\
\hline & & Fully agreed & agreed & General & Disagreed & Fully disagreed \\
\hline \multirow[t]{3}{*}{$\begin{array}{l}\text { Cultural preservation } \\
\text { level }\end{array}$} & $\begin{array}{l}\text { Q7 Do you think the } \\
\text { training has enhanced } \\
\text { your own design skills? }\end{array}$ & & & & & \\
\hline & $\begin{array}{l}\text { Q8 Do you think that } \\
\text { training enriches } \\
\text { cultural activities in } \\
\text { the countryside? }\end{array}$ & & & & & \\
\hline & $\begin{array}{l}\text { Q9 Do you think the } \\
\text { training has increased } \\
\text { the cultural exchange } \\
\text { channels between the } \\
\text { village and the outside } \\
\text { world? }\end{array}$ & & & & & \\
\hline \multirow[t]{3}{*}{$\begin{array}{l}\text { Social relationship } \\
\text { level }\end{array}$} & $\begin{array}{l}\text { Q10 Do you think that } \\
\text { design intervention } \\
\text { has increased enthusi- } \\
\text { asm and participation? }\end{array}$ & & & & & \\
\hline & $\begin{array}{l}\text { Q11 Do you think that } \\
\text { design intervention } \\
\text { has increased employ- } \\
\text { ment opportunities in } \\
\text { rural areas? }\end{array}$ & & & & & \\
\hline & $\begin{array}{l}\text { Q12 Do you think that } \\
\text { design intervention } \\
\text { has increased the } \\
\text { cultural identity within } \\
\text { the village? }\end{array}$ & & & & & \\
\hline
\end{tabular}

\section{Abbreviations}

ANT: Actor-network theory; DPA: Design for poverty alleviation; OPP: Obligatory passage point; OR: Odds ratio; SDGs: Sustainable development goals; ZMET: Zaltman metaphor elicitation technique.

\section{Acknowledgements}

We would like to thank the craftsmen in Shengzhou for their supports of this research.

\section{Authors' contributions}

Conceptualization: WL; methodology: WL, HK and ZL; validation: ZL, formal analysis: $W L$ and $Z L$; investigation: $W L$ and $Z L$; resources: $W L$; Data curation: $W L$; writing —original draft preparation: WL and ZL; writing — review and editing: WL and HK; project administration: WL and HK; funding acquisition: WL. All authors read and approved the final manuscript.

\section{Funding}

This research was funded by Humanities and Social Science Fund of Ministry of Education of China, Grant Number 19YJC760046.

\section{Availability of data and materials}

The datasets used and/or analysed during the current study are available from the corresponding author on reasonable request.

\section{Declarations}

\section{Competing interests}

The authors declare that they have no competing interests.

Received: 18 August 2021 Accepted: 15 December 2021

Published online: 06 January 2022

\section{References}

1. Murray R, Caulier-grice J, Mulgan G. The open book of social innovation London: NESTA; 2010.

2. Loorbach D, Wittmayer J, Avelino F, Wirth TV, Frantzeskaki N. Transformative innovation and translocal diffusion. Environ Innov Soc Trans. 2020;6:251-60. https://doi.org/10.1016/j.eist.2020.01.009.

3. Pol E, Ville S. Social innovation: buzz word or enduring term? J SocioEcon. 2009;6:878-85. https://doi.org/10.1016/j.socec.2009.02.011.

4. Spangenberg JH, Fuad-Luke R, Blincoe R. Design for sustainability (DfS): interface of sustainable production and consumption. J Clean Prod. 2010;18:1485-93. https://doi.org/10.1016/j.jclepro.2010.06.002.

5. Busch O, Palmås K. Social means do not justify corruptible ends: a realist perspective of social innovation and design. She Ji J Des Econ Innov. 2016:4:275-87. https://doi.org/10.1016/j.sheji.2017.07.002.

6. Ou JY, Zhang HN. Research on the design strategy of rural cultural revitalization service under the guidance of social innovation vision. Packag Eng. 2020;3:1-7.

7. Sustainable Development Goals. United Nations sustainable development-17 goals transform our word. 2015. https://www.un.org/susta inabledevelopment/. Accessed 27 Aug 2020.

8. Li CD, Zhu L, Meng SN. 2018: changes and pains of design research. China Lit Art Crit. 2019;2:49-59.

9. Carrozzino M, Scucces A, Leonardi R, Evangelista C, Bergamasco M. Virtually preserving the intangible heritage of artistic handicraft. J Cult Heritage. 2011;12:82-7. https://doi.org/10.1016/j.culher.2010.10.002.

10. Dou J, Qin J, Jin Z, Li Z. Knowledge graph based on domain ontology and natural language processing technology for Chinese intangible cultural heritage. JVis Lang Comput. 2018;10:19-28. https://doi.org/10.1016/j.jvlc. 2018.06.005.

11. Song $X T$, Yang $Y Z$, Yang $R$, Shafi M. Keeping watch on intangible cultural heritage: live transmission and sustainable development of Chinese lacquer art. Sustainability. 2019;7:3868. https://doi.org/10.3390/su11143868. 
12. Fan KK, Feng TT. Discussion on sustainable development strategies of the traditional handicraft industry based on Su-style furniture in the Ming dynasty. Sustainability. 2019;11:2008. https://doi.org/10.3390/su110 72008.

13. Masoud H, Mortazavi M, Torabi FN. A study on tourists'tendency towards intangible cultural heritage as an attraction (case study: Isfahan, Iran). City Cult Soc. 2019;17:54-60. https://doi.org/10.1016/j.ccs.2018.11.001.

14. Pang LS. On the construction of rural culture. J Shandong Univ Art Des. 2012:5:4-6.

15. Aromdee K.. Home-Korakot bamboo handicraft, phetchaburi Thaliand. 2020. https://korakot.net/. Accessed 10 Aug 2020.

16. Tang LL. A comparative study on the clustering development of rural traditional handicrafts in four Asian countries. Cult Heritage. 2019;3:39-46.

17. Li QS. Development modes and cases analysis of rural tourism in Japan. Contemp Econ Jpn. 2020;2:72-80.

18. Boonlaor N, Chuenrudeemol W. Design promises: the case study of Bangchaocha bamboo basketry community. Des Front Terri Concepts Technol. 2014;1:115-20. https://doi.org/10.5151/design-icdhs-025.

19. Song $\mathrm{JH}$. Cultural production and productive safeguarding of intangible cultural heritage. Cult Heritage. 2012;1(1):5-157.

20. Liu HL. New mode of intangible cultural heritage protection in the era of cultural and creative industries. Art Sci Technol. 2017;1:73-5.

21. Chan JKH. Design ethics: reflecting on the ethical dimensions of technology, sustainability, and responsibility in the Anthropocene. Des Stud. 2018;54:184-200. https://doi.org/10.1016/j.destud.2017.09.005.

22. Zhang B, Shao DS. Three definitions of the concept of "poverty alleviation by design." Art Life J FuZhou Univ. 2019;2:18-22.

23. Maruya K, Yamashita S, Uchiyama T. Community spaces in the minds of traditional craftsmen in a pottery village in Japan. Front Archit Res. 2015;4:253-62. https://doi.org/10.1016/j.foar.2015.05.002.

24. Xu GL. Productive protection of handicrafts: returning to life or going to art. Natl Arts. 2017;3:53-60.

25. Manzini E, Coad R, Friedman K, Stolterman E. Design, when everyone designs. Cambridge: MIT Press; 2015.

26. Ciftci GH, Walker S. Design for grassroots production in eastern Turkey through the revival of traditional handicrafts. Des J. 2017;9:S2991-3004. https://doi.org/10.1080/14606925.2017.1352808.

27. Latour B. Science in action: how to follow scientists and engineers through society. Boston: Harvard University Press; 1987.

28. Callon M. Some elements of a sociology of translation: domestication of the scallops and the fishermen of St Brieux Bay. Sociol Rev. 1984;32:196223. https://doi.org/10.1111/j.1467-954X.1984.tb00113.x.

29. Liu X, Wang XY. A Review on the application of actor network theory to human geography. Prog Geogr. 2013;7:1139-47. https://doi.org/10. 11820/dlkxjz.2013.07.016.

30. Secinaro S, Brescia V, Calandra D, Biancone P. Towards a hybrid model for the management of smart city initiatives. Cities. 2021;116: 103278. https://doi.org/10.1016/j.cities.2021.103278.

31. Sage D, Vitry C, Dainty A. Exploring the organizational proliferation of new technologies: an affective actor-network theory. Organ Stud. 2020;41(3):345-63. https://doi.org/10.1177/0170840618815524.

32. Ryfe D. Actor-network theory and digital journalism. Digit J. 2021. https:// doi.org/10.1080/21670811.2021.1945937.

33. Devi WP, Kumar H. Frugal innovations and actor-network theory: a case of bamboo shoots processing in Manipur, India. Eur J Dev Res. 2018;30:6683. https://doi.org/10.1057/s41287-017-0116-1.

34. Sarker S, Sarker S, Sidorova A. Understanding business process change failure: an actor-network perspective. J Manag Inf Syst. 2014;12:51-86. https://doi.org/10.2753/MIS0742-1222230102

35. Latour B. Reassembling the social: an introduction to actor-networktheor. Oxford: Oxford University Press; 1983.

36. John L. Notes on the theory of the actor-network: ordering, strategy, and heterogeneity. Syst Prac Action Res. 1992;1992(5):379-93. https://doi.org/ 10.1007/BF01059830.

37. Callon M. Actor-network theory-the market test. Sociol Rev. 1999;47:181-95.

38. Gaver B, Dunne T, Pacenti E. Design: cultural probes. Interact. 1999;6:21-9. https://doi.org/10.1145/291224.291235.

39. Oulasvirta A, Kurvinen E, Kankainen T. Understanding contexts by being there: case studies in bodystorming. Pers Ubiquit Comput. 2003;2:125-34 https://doi.org/10.1007/s00779-003-0238-7.
40. Zhang DD. Embodied cognition at risk: anthropological reflect on designers involving in local traditional handicrafts. J Nanjing Arts Inst. 2016;2(36):40-187.

41. Likert R, Roslow S, Murphy G. A simple and reliable method of scoring the thurstone attitude scales. Pers Psychol. 2006;46(3):689-90.

42. McCullagh P. Regression models for ordinal data. J R Stat Soc Ser B. 1980;42:109-42.

43. Stoltzfus J. Logistic regression: a brief primer. Acad Emerg Med. 2011;18(10):1099-104. https://doi.org/10.1111/j.1553-2712.2011.01185.x.

44. Sperandei S. Understanding logistic regression analysis. Biochem Med. 2014;24(1):12-8. https://doi.org/10.11613/BM.2014.003.

45. Sun ZQ. Medical statistic. Beijing: People's Medical Publishing House; 2014.

\section{Publisher's Note}

Springer Nature remains neutral with regard to jurisdictional claims in published maps and institutional affiliations.

\section{Submit your manuscript to a SpringerOpen ${ }^{\circ}$ journal and benefit from:}

- Convenient online submission

- Rigorous peer review

- Open access: articles freely available online

- High visibility within the field

- Retaining the copyright to your article

Submit your next manuscript at $\boldsymbol{\nabla}$ springeropen.com 